\title{
Does the responsibility that patients exert determine their opportunities for best clinical practice in the healthcare system?
}

\author{
VIBE BOLVIG HYLDGÅRD ${ }^{1,2 *}$ \\ SØREN PAASKE JOHNSEN ${ }^{3}$ \\ HENRIK STØVRING ${ }^{4,5}$ \\ ANDREAS ALBERTSEN ${ }^{6}$ \\ RIKKE SØGAARD ${ }^{1,7}$ \\ ${ }^{1}$ Department of Public Health - Aarhus University, Denmark \\ ${ }^{2}$ Health economics, DEFACTUM, Central Region Denmark, Denmark \\ ${ }^{3}$ Danish Center for Clinical Health Services Research, Department of Clinical Medicine, Aalborg University \\ Hospital, Denmark \\ ${ }^{4}$ Department of Public Health - Biostatistics, Aarhus University, Denmark \\ ${ }^{5}$ Research Unit of Clinical Pharmacology and Pharmacy, Department of Public Health, University of \\ Southern Denmark, Denmark \\ ${ }^{6}$ Department of Political Science - School of Business and Social Sciences, Aarhus University, Denmark \\ ${ }^{7}$ Department of Clinical Research, University of Southern Denmark, Denmark
}

\begin{abstract}
Many consider inequality in health unfair if it is caused by inequality within the healthcare system but less unfair when caused by individuals' health behaviour. However, healthcare systems are challenged when it comes to ensuring equal care for equal need. In Roemer's equality of opportunity theory, people have equal opportunity for obtaining something if obtaining it reflects their effort instead of their circumstances. Very little is known about how responsibility exerted by patients prior to illness affects the healthcare they are provided by the healthcare system. We aimed to apply Roemer's theory to an acute care setting where healthcare is most directly in the hands of the healthcare system in order to study the role of patient-exerted responsibility for their opportunities in the healthcare system. We operationalised the responsibility patients exert as Body Mass Index (BMI), smoking and alcohol habits, and their circumstances as demographics, socioeconomics, prognostic factors and year of discharge. Opportunity in healthcare was defined as patients' attainment of clinical guideline-recommended acute hospital care. In Roemer's theory, we detected inequality of opportunity as restricted attainment of healthcare was mainly associated with patients' circumstances, such as lower education, old age or living alone. We also identified a strong association with BMI; being underweight negatively affected patients' opportunities as it led to suboptimal healthcare, while the opposite was found for being overweight and, in particular, obese. Hence, patient-exerted responsibility affected patients' opportunities in healthcare, though perhaps in an unexpected way. This improved understanding of inequality may help to focus future research and, in the long term, support clinical and political efforts to achieve equal care for equal needs.
\end{abstract}

JEL classification: I14 Health and Inequality

Key words: Equality of opportunity, Patient exerted responsibility, Healthcare inequality

* Correspondence to: Vibe Bolvig Hyldgård, Department of Public Health - Aarhus University. Bartholins Alle 2, 8000 Aarhus C, Denmark. Email: vibe.bolvig@rm.dk.

Published: Online March 2021. dx.doi.org/10.5617/njhe.7822 


\section{Introduction}

Despite decades of political goals about equality in access, inequality in access to best clinical practice remains a problem. Healthcare systems may aggravate inequality in health, and this is considered unfair when it is avoidable (Lutfey et al., 2008; Carrieri and Jones, 2018; Davillas and Jones, 2020). A leading goal in health policy is to ensure equal access for equal needs (Van Doorslaer, Masseria and Koolman, 2006). This political goal is visible in decades of effort that includes establishing formal clinical guidelines and ongoing monitoring of healthcare provision. However, numerous examples show the system failing to ensure equality as patient characteristics are repeatedly linked to differences in the healthcare services actually attained (Morris, Sutton and Gravelle, 2005; Siciliani and Verzulli, 2009; Kjellén, Von Euler-Chelpin and von Euler-Chilpin, 2010; Starr et al., 2013; Libungan et al., 2014; Carlsen and Martin, 2015). The underlying mechanisms of these inequalities are unclear and may include controversial phenomena.

Much of the literature exploring this inequality pertains especially to socioeconomic differences in waiting times, specialists visits and patients' utilisation of screening programmes, which reflects a hypothesis that resourceful patients are more successful in navigating the system and obtaining more healthcare services (Siciliani and Verzulli, 2009; Kjellén, Von Euler-Chelpin and von Euler-Chilpin, 2010; Carlsen and Martin, 2015; Terraneo, 2015; Schütte et al., 2018; Søgaard and Lindholt, 2019). In this regard, health literacy is a popular explanation for observed inequality because it covers a range of factors such as patient resources and competencies in accessing the best clinical practice through informed communication with health professionals. Grossman's demand for health framework has also been applied. This framework views health as a commodity that individuals build up and invest in over time (Grossman, 1972). According to Grossman's theory, this production of health is most efficient among individuals with higher educational levels and consequently better health literacy, which leads to socioeconomic inequality. However, such explanations are mainly relevant for elective and longstanding pathways; but disparities are also found in the field of acute care where the patients' health literacy is arguably less crucial to access and quality of care (Eden et al., 2008; Vassileva et al., 2013; Libungan et al., 2014). Focusing on acute care, a continuum of possible explanations on the part of the system might include stigmatization - if patients who have exerted objective responsibility by not smoking, not being obese or not over-drinking are favoured over patients not showing such objective responsibility. At the other end of this continuum, there is paternalism - if health professionals consider the risk factors of smoking, obesity and over-drinking the responsibility of the system as opposed to the responsibility of the individual and therefore favour 'non-responsible' patients. An alternative model of explanation could be that healthcare professionals knowingly or unknowingly allocate more resources to patients with the best prognoses.

In this study, we adopt a theoretical framework that distinguishes between patients' circumstances versus the responsibility they exert over their health (e.g. by not smoking) in order to explore possible explanations on the part of the system for inequality in access to best clinical practice when patients are in need of acute care. We use the clinical case of acute stroke for several reasons. In addition to the large homogenous patient group, stroke also represents a relevant case for our research focus as inequality in care remains despite relatively uniform needs among patients (Palnum et al., 2008, 2009; Langagergaard et al., 2011; Kimball et al., 2014; R. Chen et al., 2014). The situation for these patients is severe, and they are admitted acutely under the same clinical guidelines. Furthermore, acute stroke care is highly regulated and has been monitored in a comprehensive national database for more than a decade, an effort which does not seem to have affected inequality 
(Hyldgård et al., 2019). The aim of our study was thus to assess whether and how the responsibility exerted by patients in similar circumstances appears to affect their access to best clinical practice.

\section{METHODS}

\subsection{Analytical framework}

Roemer's "A Pragmatic Theory of Responsibility for the Egalitarian Planner" (Roemer, 1993) was adopted for this study. Roemer's theory conceptualises the ideal of equality of opportunity. In Roemer's words, "equality of opportunity for $X$ holds when the values of $X$ for all those who exercised a comparable degree of responsibility are equal, regardless of their circumstances" (Roemer, 1993). According to Roemer, people have equal opportunity to obtain something if obtaining it reflects their effort, which they are responsible for, as opposed to their circumstance. Such reasoning could be considered a justification of real-world policies which emphasize personal responsibility. Prominent examples are co-payment for dental health in Germany (Schmidt, 2008); the Dutch inclusion of personal responsibility as a criterion for rationing (Tinghög, Carlsson and Lyttkens, 2010) and practices in Florida, where obesity was recently considered a reason to deny certain treatments (Eyal, 2013). Such policies and the principles that underpin them are, of course, controversial (Feiring, 2008; Nielsen and Axelsen, 2012; Friesen, 2018; Albertsen, 2020). Here, we apply Roemer's approach for analytical purposes. We apply the framework to explore whether patients obtain care that matches their need. Inspired by Roemer's distinction between circumstances and responsibility, we categorise the various factors that could influence whether patients receive the required healthcare. As clinical guidelines define what a patient population should uniformly receive, we can assess which factors explain deviations, and thereby what contributes to healthcare inequality. There is, of course, an important difference between the ideal of equality of opportunity and the ideal of equal treatment according to need, as required by Danish law. The crucial difference is that, for the former, it is not problematic if differences reflect people exercising responsibility. This article is not about which of these ideals are preferable. Rather, we analyse the case from the perspective of equality of opportunity, precisely because categorising factors in terms of whether they are part of circumstances or affected by exercising responsibility provides valuable knowledge about what matters for the healthcare obtained. This approach helps us understand inequalities in healthcare and the mechanisms driving some of the differences in treatment outcomes. We developed an empirical model that specifies how the extent to which a patient receives guidelinerecommended care is explained by responsibilities and circumstances.

\subsection{Study design}

This study was performed in a national setting of publicly funded hospitals where all acute stroke care is provided. The study is based on patient-level register data from several national registers under Statistics Denmark and from the Danish Stroke Register (DSR), where data are gathered by the healthcare personnel treating the patients (Lynge, Sandegaard and Rebolj, 2011; Petersson, Baadsgaard and Thygesen, 2011; Wildenschild et al., 2013). Reporting to the DSR is mandatory for all departments treating acute stroke patients. The DSR is a validated nationwide clinical quality database with an estimated sensitivity of 97\% (Wildenschild et al., 2013). The cohort of consecutive stroke patients discharged from 2004 to 2014 was identified in the DSR, and the data were linked to several national registers under Statistics Denmark using personal identification numbers (Lynge, Sandegaard and Rebolj, 2011; Petersson, Baadsgaard and Thygesen, 2011). 


\subsection{Patient characteristics}

A literature review was undertaken to identify what characteristics to include under circumstances and responsibilities in the context of stroke. Responsibilities included characteristics identified through studies of behavioural risk factors (Cox et al., 2006; X. Chen et al., 2014; Boehme, Esenwa and Elkind, 2017). Consequently, national registers and the DSR were searched for the identified characteristics; and when available, they were acquired for the study. From the DSR, data on health behaviour (alcohol habits, smoking habits and Body Mass Index (BMI in $\left.\mathrm{kg} / \mathrm{m}^{2}\right)$ ) were retrieved.

Patients' circumstances included characteristics identified in the quality agenda of the Danish Regions, the DSR's annual reports and Scandinavian studies of inequality in healthcare (Palnum et al., 2008, 2009; Langagergaard et al., 2011; Starr et al., 2013; Carlsen and Martin, 2015). The DSR provided the following characteristics: age, gender, civil situation and accommodation. Statistics Denmark provided data on disposable household income, education, children in the household and origin, all from the year of discharge. Data on employment status and personal disposable income were provided by Statistics Denmark for the year prior to discharge. To adjust for residual differences in needs and thus potential confounding factors, adjustments were made for contact to general practitioners and other primary sector contacts obtained from Statistics Denmark from one year prior to discharge. Likewise, we adjusted for the following prognostic factors drawn from the DSR: type of stroke, Scandinavian Stroke Scale (SSS) (an instrument for stratifying stroke severity (Lindenstrøm et al., 1991) and previously diagnosed diabetes, hypertension and strokes. Lastly, adjustments were made for the patients' municipality, year of hospital discharge and the departments providing healthcare, obtained from Statistics Denmark and the DSR.

\subsection{Best clinical practise}

We defined best clinical practise as guideline-recommended care using clinical performance measures obtained from the DSR. The clinical guidelines cover all stroke patients and are in accordance with the guidelines of the European Stroke Organisation and the American Heart Association (Johnsen et al., 2016). The performance measures reflect the provision of core processes which include diagnostics, treatment and early rehabilitation (see (Hyldgård et al., 2019) for a detailed list of the performance measures and (Dansk Selskab for Apopleksi, 2013) for the clinical guidelines). Based on national, detailed written instructions, the hospital personnel classifies every patient as eligible or not for each of the performance measures that are available at the time according to the type of stroke and the presence of contraindications (Palnum et al., 2009; Johnsen et al., 2016). This means that each performance measure that ultimately makes up our outcome, is need-adjusted such that the scoring represents fully homogenous patients. The three responsibility characteristics - BMI, smoking habits and alcohol consumption - are not specified among the potential contraindications for any of the performance measures. Over the studied period, the number of performance measures relevant for this study increased from 8 to 16 as the clinical guidelines evolved due to advancements in acute stroke care.

\subsection{Statistical analysis}

We computed an aggregated outcome for each patient, which was transformed into empirical logs in order to minimise estimation bias (Gart and Zweifel, 1967; McCullagh and Nelder, 1989; Donnelly and Verkuilen, 2017; Hyldgård et al., 2019): 


$$
Z=\log \left(\frac{y+\frac{1}{2}}{m-y+\frac{1}{2}}\right)
$$

where $Z$ is the model outcome. For each person, a number of relevant performance measures could be expected to be fulfilled. Each of these measures is binary (fulfilled or not), and we let $y$ be the total number of fulfilled measures, and $m$ the total number of medically relevant measures. Accordingly, $y / m$ is the proportion of fulfilled measures. All characteristics were analysed simultaneously in one model, which was estimated using linear regression. We used the analytical weight $w$ to satisfy the assumption of linear regression of homogeneous variance (Gart and Zweifel, 1967; McCullagh and Nelder, 1989; Donnelly and Verkuilen, 2017):

$$
w=\left(y+\frac{1}{2}\right)^{-1}+\left(m-y+\frac{1}{2}\right)^{-1}
$$

The interpretation of the results follows that of a logistic regression; i.e., the exponential of the coefficient represents the odds ratio (OR) associated with a 1-unit change in the covariate (see the appendix for a more technical description). Finally, multilevel modelling was used as the patient level was nested within the hospital department level.

Model predictions for four types of patients were contrasted: 1) a responsible patient and 2) an irresponsible patient defined by varying only responsibility characteristics and keeping the circumstance characteristics at reference level, 3) the worst-off patients and 4) the best-off patients, defined by the 5\% lowest and highest predicted fulfilment outcomes, respectively. The model predictions for these four types of patients were translated into fulfilment percentages of guideline-recommended care.

All estimates are reported with 95\% confidence intervals (CI). Stata SE 14.2 (StataCorp) was used.

\subsection{Sensitivity analyses}

Proceeding with the same model in which all characteristics were included we performed following sensitivity analyses: For handling missing observations in the responsibility and circumstance characteristics, we applied two approaches: we 1) included an indicator for missing observation in each characteristic, and 2) replaced missing observations with the levels associated with the worst/best outcome, respectively. To test an alternative operationalisation of guideline-recommended care, we defined a dichotomous all-or-none outcome (whether each patient received all of the relevant measures or not). As an alternative to the empirical logistic approach, we tested a logistic regression model with random effects using each indicator as the unit of analysis.

\section{Results}

A total of 110,848 individual stroke patients were studied, of whom 41,864 had complete data sets. Descriptive characteristics of the study population and the distribution of missing observations are illustrated in Table 1 . In total, $77 \%$ of the patients drank within the national recommendation, $52 \%$ were non-smokers at the time of admission and $29 \%$ had a normal BMI. Dominating circumstance characteristics included Danish origin, own home accommodation, retirement (which includes receiving disability pension) and primary education. BMI was the most common missing observation as a third of the patients were registered with an unknown BMI. 
Table 1: Characterisation of the study population. Values are numbers (\%) unless otherwise stated.

\begin{tabular}{|c|c|c|c|}
\hline & & $\begin{array}{l}\text { Patients with no } \\
\text { missing data } \\
(\mathrm{n}=41,864)\end{array}$ & $\begin{array}{l}\text { All patients } \\
(\mathrm{n}=110,848)\end{array}$ \\
\hline \multirow{3}{*}{$\begin{array}{l}\text { Alcohol } \\
\text { consumption }\end{array}$} & $\begin{array}{l}\text { Less than } 7 / 14 \text { units per week for } \\
\text { women } / \text { men }\end{array}$ & $37,758(90.2)$ & $85,433(77.1)$ \\
\hline & Above $7 / 14$ units per week for women/men & $4,106(9.8)$ & $9,282(8.4)$ \\
\hline & Unknown & & $16,133(14.6)$ \\
\hline \multirow{4}{*}{ Smoking } & Never & $14,494(34.6)$ & $32,881(29.7)$ \\
\hline & Current & $15,792(37.7)$ & $34,660(31.3)$ \\
\hline & Previous & $11,578(27.7)$ & $24,239(21.9)$ \\
\hline & Unknown & & $19,068(17.2)$ \\
\hline \multirow{5}{*}{ BMI $\left(\mathrm{kg} / \mathrm{m}^{2}\right)$} & Underweight $(<18.5)$ & $1,449(3.5)$ & $3,353(3.0)$ \\
\hline & Normal weight (18.5-24) & $17,330(41.4)$ & $32,220(29.1)$ \\
\hline & Overweight (25-29) & $15,286(36.5)$ & $25,399(22.9)$ \\
\hline & Obese $(>30)$ & $7,799(18.6)$ & $12,536(11.3)$ \\
\hline & Unknown & & $37,340(33.7)$ \\
\hline \multirow{4}{*}{ Age group } & $<65$ & $14,067(33.6)$ & $31,879(28.8)$ \\
\hline & $65-74$ & $12,429(29.7)$ & $27,863(25.1)$ \\
\hline & $75-84$ & $12,208(29.2)$ & $32,053(28.9)$ \\
\hline & $>85$ & $3,160(17.2)$ & $19,053(17.2)$ \\
\hline \multirow{2}{*}{ Gender } & Female & $18,504(44.2)$ & $52,578(47.4)$ \\
\hline & Male & $23,360(55.8)$ & $58,270(52.6)$ \\
\hline \multirow{2}{*}{ Origin } & Danish & $40,574(96.9)$ & $106,152(95.8)$ \\
\hline & Immigrant or first-generation descendant & $1,290(3.1)$ & $4,696(4.2)$ \\
\hline \multirow{3}{*}{ Civil situation } & Cohabitant & $25,324(60.5)$ & $57,929(52.3)$ \\
\hline & Living alone & $16,540(39.5)$ & $45,875(41.4)$ \\
\hline & Unknown^ $^{\wedge}$ & & $7,044(6.4)$ \\
\hline Children in the & No & $37,611(89.8)$ & $101,312(91.4)$ \\
\hline \multirow[t]{2}{*}{ household } & Yes & $4,253(10.2)$ & $9,536(8.6)$ \\
\hline & Own home & $40,687(97.2)$ & $95,700(86.3)$ \\
\hline \multirow[t]{2}{*}{ Accommodation } & Assisted living facility & $1,177(2.8)$ & $7,710(7.0)$ \\
\hline & Unknown^ & & $7,438(6.7)$ \\
\hline \multirow{4}{*}{$\begin{array}{l}\text { Family disposable } \\
\text { income (by tertile), } \\
\text { mean (SD) }\end{array}$} & Low & $138,763(126,145)$ & $137,247(91,225)$ \\
\hline & Middle & $217,987(28,017)$ & $214,670(28,150)$ \\
\hline & High & $463,949(526,172)$ & $460,447(432,077)$ \\
\hline & Unknown, n (\%) & & $10,126(9.1)$ \\
\hline \multirow{4}{*}{$\begin{array}{l}\text { Personal disposable } \\
\text { income (by tertile), } \\
\text { mean (SD) }\end{array}$} & Low & $103,904(82,574)$ & $103,262(63,178)$ \\
\hline & Middle & $158,383(13,361)$ & $157,990(13,396)$ \\
\hline & High & $290,567(263,557)$ & $289,964(317,705)$ \\
\hline & Unknown, n (\%) & & $9(<0.1)$ \\
\hline \multirow{4}{*}{ Employment status } & Working & $9,809(23.4)$ & $20,419(18.4)$ \\
\hline & Retired (including disability pension) & $30,814(73.6)$ & $86,166(77.7)$ \\
\hline & Unemployed & $1,241(3.0)$ & $3,140(2.8)$ \\
\hline & Unknown^ & & $1,123(1.0)$ \\
\hline \multirow{4}{*}{$\begin{array}{l}\text { Highest achieved } \\
\text { education }\end{array}$} & Primary & $19,585(46.8)$ & $47,251(42.6)$ \\
\hline & Upper secondary & $15,898(38.0)$ & $35,716(32.2)$ \\
\hline & Higher & $6,381(15.2)$ & $14,545(13.1)$ \\
\hline & Unknown & & $13,336(12.0)$ \\
\hline \multirow{4}{*}{$\begin{array}{l}\text { GP contacts (by } \\
\text { tertile), mean (SD) }\end{array}$} & Low & $3.7(2.6)$ & $3.8(2.6)$ \\
\hline & Middle & $14.3(3.7)$ & $14.4(3.7)$ \\
\hline & High & $39.1(18.9)$ & $40.1(19.9)$ \\
\hline & Unknown, n (\%) & & $4,053(3.7)$ \\
\hline \multirow{4}{*}{$\begin{array}{l}\text { Non-GP contacts in } \\
\text { primary sector (by } \\
\text { tertile), mean (SD) }\end{array}$} & Low & $0.6(0.8)$ & $0.5(0.8)$ \\
\hline & Middle & $5.6(1.9)$ & $5.6(1.9)$ \\
\hline & High & $29.3(33.7)$ & $32.5(38.7)$ \\
\hline & Unknown, n (\%) & & $4,053(3.7)$ \\
\hline
\end{tabular}

${ }^{\wedge}$ For civil situation, accommodation and employment status unknown include both missing registrations and registrations as "other".

The main analysis of patients with no missing observations is shown in Table 2 alongside the primary sensitivity analysis based on the entire population. Both analyses show that - when adjusted for all characteristics - responsible behaviour (drinking within 
the recommended limits, refraining from smoking and having a normal range BMI ) does not translate to receiving guideline-recommended care. Smoking and alcohol habits are not associated with guideline-recommended care, and the identified dose-response association found in relation to BMI did not correspond to the theoretical framework as increasing BMI was associated with increasing care. Compared to having a normal BMI, an underweight patient's odds of having one additional relevant performance measure fulfilled were $36 \%$ lower (OR $=0.64(95 \% \mathrm{CI}: 0.45-0.92))$, whereas the odds for an obese patient were $20 \%$ higher $(\mathrm{OR}=1.20(95 \% \mathrm{CI}: 1.08-1.34)$ ). The association with BMI was present in the entire decade but varied over time, so the results were adjusted for this interaction. The association with obesity was reduced over time, but it remained positive.

Among the circumstance characteristics, increasing age was associated with a decreasing proportion of guideline-recommended care. Living alone and being retired were also negatively associated with guideline-recommended care.

Patients received an increasing proportion of guideline-recommended care over time. Transforming the estimates of Table 2 to the normal scale shows an increase in the predicted proportion of best clinical practice for a reference patient from 69\% (95\% CI: 62 - 74) in 2004 to $84 \%$ (95\% CI: 81- 87) a decade later.

The sensitivity analyses all supported the findings; only the magnitude of the identified associations varied slightly. Including indicators of missing observations in each characteristic produced stronger associations related to BMI and alcohol habits (cf. Table 2 ). In the worst- and best-case scenario analyses, the identified tendencies were emphasised. The sensitivity analysis of the all-or-none outcome of the core treatment elements similarly supported the findings. A random effects model similarly supported the findings. Hence, the results are robust for both different handlings of missing observations and different formulations of the outcome measure. The results of the missing indicator analysis are outlined in Table 2, and the remaining sensitivity analyses are not shown but can be produced on request. In accordance with public health literature, we observed some correlation between patients' responsibility and circumstances, but we found no evidence of effect modification when testing for an interaction between these. Hence, the effect of the responsibility characteristics on guideline-recommended care was not modified by circumstance characteristics. With respect to potential residual differences in needs, we also tested whether the effect of patient-exerted responsibility was modified by stroke severity, and found that it was not.

Drawing on the findings of the analysis of patients with no missing observations, Table 3 outlines how the characteristics are distributed among the four patient types: the $5 \%$ worst/best-off and the theoretically responsible and irresponsible patients. The distribution of the characteristics in the predicted worst- and best-off patients supported the findings shown in Table 2, though with a few additions: a clear over-representation of low family income, retirement and primary education in the worst-off group, and the opposite in the best-off group. Table 3 further underlines that patient-exerted responsibility was not associated with receiving guideline-recommended care. The proportion of guideline-recommended care these patient types are predicted to receive varies by more than 25 percentage points when the worst-off are compared to the best-off, whereas responsible and irresponsible patients only vary by 1.5 percentage points. 
Table 1: Inequality in terms of receiving guideline-recommended care, Adjusted ${ }^{\dagger}$ OR (95\% CI)

\begin{tabular}{|c|c|c|c|}
\hline & & $\begin{array}{l}\text { Patients with no } \\
\text { missing } \\
\text { observations } \\
(\mathrm{n}=41,864)\end{array}$ & $\begin{array}{l}\text { All patients } \\
\text { (with missing } \\
\text { observation indicators) } \\
(\mathrm{n}=110,848)\end{array}$ \\
\hline \multirow{3}{*}{$\begin{array}{l}\text { Alcohol } \\
\text { consumption }\end{array}$} & Less than $7 / 14$ units per week for women/men & Ref. & Ref. \\
\hline & Above $7 / 14$ units per week for women/men & $0.94(0.89-1.01)$ & $0.89(0.83-0.94)$ \\
\hline & Unknown & & $0.90(0.86-0.94)$ \\
\hline \multirow{4}{*}{ Smoking } & Never & Ref. & Ref. \\
\hline & Current & $0.99(0.95-1.03)$ & $1.02(0.99-1.05)$ \\
\hline & Previous & $0.99(0.95-1.03)$ & $1.00(0.96-1.04)$ \\
\hline & Unknown & & $0.91(0.87-0.96)$ \\
\hline \multirow{5}{*}{ BMI $\left(\mathrm{kg} / \mathrm{m}^{2}\right)$} & Underweight $(<18.5)$ & $0.64(0.45-0.92)$ & $0.57(0.43-0.75)$ \\
\hline & Normal weight (18.5-24) & Ref. & Ref. \\
\hline & Overweight (25-29) & $1.15(1.01-1.31)$ & $1.18(1.06-1.30)$ \\
\hline & Obese $(>30)$ & $1.20(1.08-1.34)$ & $1.21(1.14-1.29)$ \\
\hline & Unknown & & $0.94(0.71-1.24)$ \\
\hline \multirow{4}{*}{ Age group } & $<65$ & Ref. & Ref. \\
\hline & $65-74$ & $0.96(0.91-1.02)$ & $1.00(0.96-1.03)$ \\
\hline & $75-84$ & $0.88(0.83-0.92)$ & $0.93(0.89-0.97)$ \\
\hline & $>85$ & $0.88(0.79-0.97)$ & $0.92(0.87-0.98)$ \\
\hline \multirow{2}{*}{ Gender } & Female & Ref. & Ref. \\
\hline & Male & $1.05(1.01-1.10)$ & $1.04(1.02-1.06)$ \\
\hline \multirow{2}{*}{ Origin } & Danish & Ref. & Ref. \\
\hline & Immigrant or first generation descendant & $0.96(0.89-1.03)$ & $0.95(0.91-1.00)$ \\
\hline \multirow{3}{*}{ Civil situation } & Cohabitant & Ref. & Ref. \\
\hline & Living alone & $0.88(0.84-0.92)$ & $0.87(0.84-0.90)$ \\
\hline & Unknown $^{\wedge}$ & & $0.92(0.85-0.98)$ \\
\hline \multirow{2}{*}{$\begin{array}{l}\text { Children in } \\
\text { the household }\end{array}$} & No & Ref. & Ref. \\
\hline & Yes & $0.98(0.93-1.03)$ & $0.99(0.96-1.03)$ \\
\hline \multirow{3}{*}{$\begin{array}{l}\text { Accommodati } \\
\text { on }\end{array}$} & Own home & Ref. & Ref. \\
\hline & Assisted living facility & $0.94(0.81-1.08)$ & $1.00(0.93-1.08)$ \\
\hline & Unknown $^{\wedge}$ & & $0.92(0.85-0.99)$ \\
\hline \multirow{4}{*}{$\begin{array}{l}\text { Family } \\
\text { disposable } \\
\text { income }\end{array}$} & Low & $0.97(0.93-1.02)$ & $0.95(0.91-0.98)$ \\
\hline & Middle & $0.99(0.96-1.02)$ & $0.98(0.96-1.01)$ \\
\hline & High & Ref. & Ref. \\
\hline & Unknown & & $0.89(0.85-0.92)$ \\
\hline \multirow{4}{*}{$\begin{array}{l}\text { Personal } \\
\text { disposable } \\
\text { income }\end{array}$} & Low & $1.02(0.98-1.07)$ & $1.02(0.99-1.06)$ \\
\hline & Middle & $1.03(1.00-1.07)$ & $1.01(0.99-1.03)$ \\
\hline & High & Ref. & Ref. \\
\hline & Unknown & & $2.49(0.89-6.97)$ \\
\hline \multirow{4}{*}{$\begin{array}{l}\text { Employment } \\
\text { status }\end{array}$} & Working & Ref. & Ref. \\
\hline & Retired & $0.94(0.88-1.00)$ & $0.91(0.86-0.95)$ \\
\hline & Unemployed & $1.03(0.95-1.11)$ & $1.02(0.95-1.09)$ \\
\hline & Unknown $^{\wedge}$ & & $0.91(0.84-0.99)$ \\
\hline \multirow{4}{*}{$\begin{array}{l}\text { Highest } \\
\text { achieved } \\
\text { education }\end{array}$} & Primary & $0.81(0.72-0.93)$ & $0.87(0.78-0.98)$ \\
\hline & Upper secondary & $0.92(0.80-1.07)$ & $0.95(0.85-1.07)$ \\
\hline & Higher & Ref. & Ref. \\
\hline & Unknown & & $0.85(0.68-1.05)$ \\
\hline \multirow{4}{*}{ GP contacts } & Low & $1.02(0.99-1.06)$ & $1.03(1.01-1.06)$ \\
\hline & Middle & Ref. & Ref. \\
\hline & High & $0.99(0.95-1.03)$ & $0.97(0.95-0.99)$ \\
\hline & Unknown & & $0.92(0.85-0.99)$ \\
\hline \multirow{4}{*}{$\begin{array}{l}\text { Non-GP } \\
\text { contacts in } \\
\text { primary sector }\end{array}$} & Low & $0.97(0.93-1.02)$ & $0.95(0.93-0.98)$ \\
\hline & Middle & Ref. & Ref. \\
\hline & High & $0.99(0.95-1.02)$ & $1.01(0.98-1.04)$ \\
\hline & Unknown & & Omitted \\
\hline Reference level & & $5.24(4.15-6.60)$ & $6.59(5.11-8.50)$ \\
\hline
\end{tabular}

OR: odds ratio, CI: confidence interval, BMI: Body mass index ${ }^{\dagger}$ The ORs are also adjusted for municipality, hypertension, diabetes, type of stroke, stroke severity, interaction between year and education and year and BMI. Coefficients not shown. ^ For civil situation, accommodation and employment status unknown include both missing registrations and registrations as "other". 
Table 3: Characteristics of four patient types and their predicted proportion of guideline-recommended care

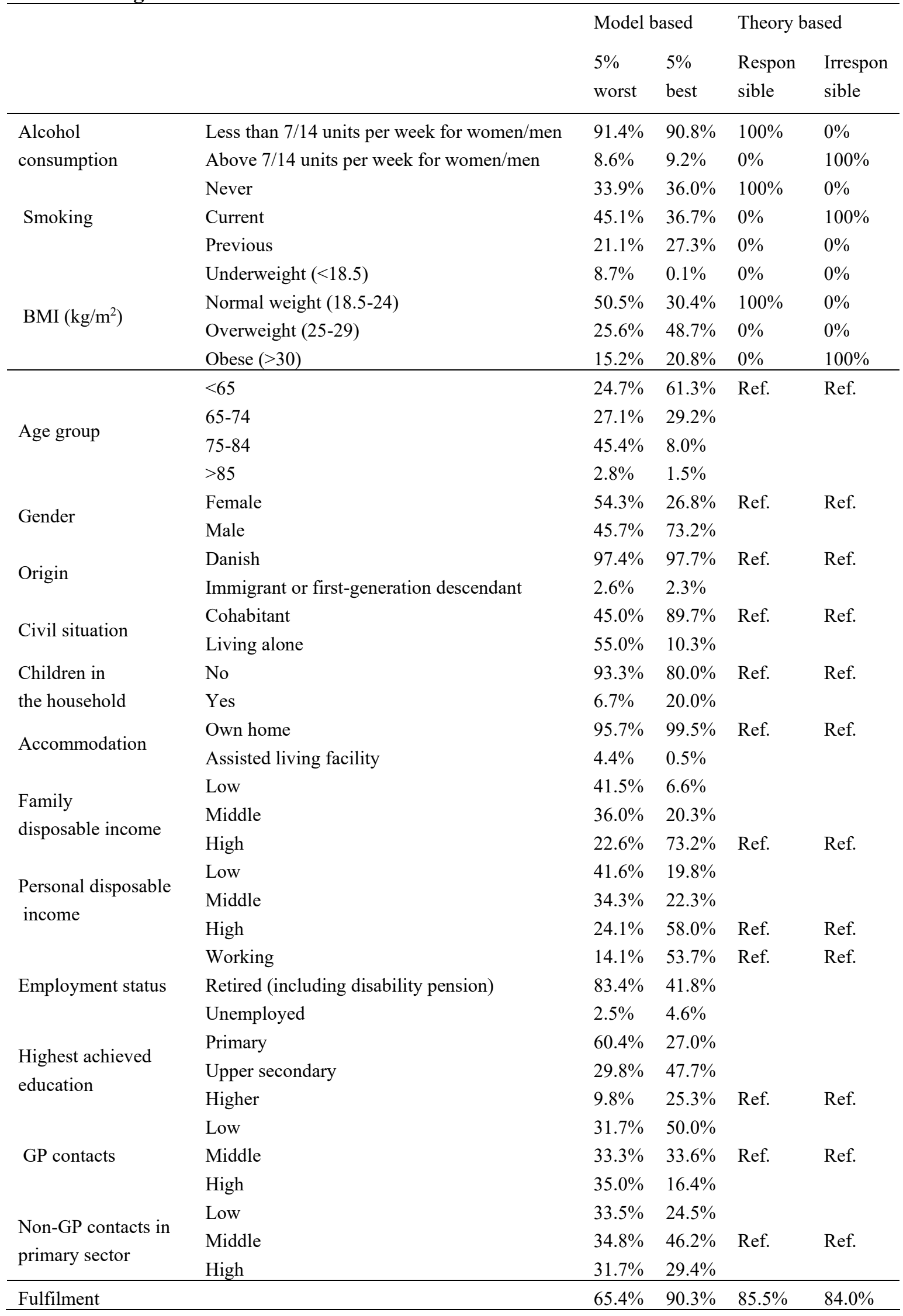




\section{Discussion}

We applied a theoretical framework to investigate what could cause inequality in opportunity for obtaining best clinical practice. Our results suggest that inequality is generally caused by circumstances rather than responsibilities. An exception, however, is that higher BMI is associated with obtaining the highest clinical quality. This raises several questions. Are our findings an indication of selection mechanisms related to stigmatisation or paternalism? Do health professionals consider obesity the responsibility of individuals or society? The nature of the responsibility characteristics differ because BMI can be observable in the acute phase whereas alcohol and smoking habits are patientreported later on in the admission. This could mean that the potential effect of alcohol and smoking habits does not fully manifest until the sub-acute phase of care, and that we have potentially underestimated theses associations.

\subsection{Comparison with other studies}

Our finding that patient circumstances, such as age, gender and education, predict access to the best clinical practice is in line with findings reported in previous studies (Palnum et al., 2008, 2009; Langagergaard et al., 2011). We are unaware of previous studies having applied Roemer's focus on responsibility characteristics. Based on Roemer's framework, we would have expected overweight and obesity to be associated with poorer clinical quality compared to normal BMI. Previous findings of stigma against obese individuals would also support such expectations (Robstad, Söderhmn and Fegran, 2018). However, we found the association to be reversed. This may be particularly interesting in the light of recent studies in the field of stroke showing that overweight and obesity are factors that are associated with better health outcomes (Andersen and Olsen, 2015; Ingeman et al., 2017).

An overall positive development in the extent to which best clinical practise was provided took place over time. In addition, time was found to modify the association between BMI and healthcare as well as education and healthcare. Changes in the BMIhealthcare association could be related to a general shift in BMI (Blundell et al., 2017) or to new knowledge about BMI as a risk factor and prognostic factor for stroke (Ingeman et al., 2017). The shift could also be related to a general shift in healthcare personnel's attitudes towards obese patients, as this may have improved over time (Budd et al., 2011).

\subsection{Main strengths and weaknesses of the study}

Since differences in needs are commonly considered a legitimate reason for inequality (Fleurbaey and Schokkaert, 2009), the homogenous needs profile of our study population represents an important strength. The analytical framework qualified and guided the selection of covariates. We applied high-quality individual-level data from nationwide validated sources. The reporting of the performance measures was closely monitored, data completeness was very high and no systematic differences in data reporting between patient subgroups have been reported (KCEB-Nord, 2014). Furthermore, registration of each performance measure contains an indication of medical relevance for the given patient. This makes for a far more nuanced outcome than had it simply stated yes or no to whether a performance measure was fulfilled. It also assists in removing residual differences in need from the analysis.

A key weakness of this study is the degree of missing data and the consequent assumption that data were missing completely at random (Sterne et al., 2009). We have no reason to believe that the fact that data were missing data was associated with both outcome and covariates. Patients with non-complete data more often lived alone, had 
severe strokes and were older than 85 years, which could explain the difficulty in collecting their information. We could not with certainty assume that data were missing at random (Sterne et al., 2009). The robustness of the results was tested in sensitivity analyses comparing the complete case analysis with either the missing observation indicator or the worst-case/best-case scenario. The results were found to be fairly insensitive to different ways of handling missing data. In addition, complete case analyses have recently been found to yield unbiased results more often than previously assumed (Bartlett, Harel and Carpenter, 2015). Working with the outcome as a proportion may also represent a weakness as each performance measure was assigned equal weight and thus considered equally important. However, the all-or-none sensitivity analysis showed that the findings were robust to other specifications of the outcome measure.

A potential weakness lies in the way in which the medical relevance of a given performance measure was marked as the clinicians had to leave the value missing when it was deemed medically irrelevant. It is therefore pertinent that missing registrations can be trusted to be purposefully missing. We had no reason to suspect that this was an issue; however, had this been the case, it could introduce uncertainties with regards to the homogeneity of needs. As a precautionary measure, we therefore adjusted for prognostic factors that could account for residual differences in needs.

\subsection{Future perspectives}

According to our findings, researchers should increase their attention to responsibility factors - specifically BMI, as it represents an important risk factor as well as prognostic factor for many diseases. The necessity to focus on BMI is stressed by the finding that being underweight is a predictor for obtaining suboptimal care. Our study also encourages a general expansion of the array of circumstance characteristics normally included in studies of equality. We urge other researchers to employ a theoretical approach in similar studies. Thus, we found the application of Roemer's equality of opportunity valuable in conducting this study. Roemer's framework may be even more fittingly applied to the field of rehabilitation or prolonged treatment as these patients' behaviour will be more noticeable than in the acute setting studied here. We call for further studies of the selection mechanisms among health professionals administering care for patients. An alternative next step in this research would be to shift the perspective from equality in healthcare towards equality in health - i.e. applying a health view in Roemer's terms - as Jones and Carrieri did in their study of equality of opportunity in health (Carrieri and Jones, 2018). No matter the focus, it is imperative that future studies take patient homogeneity into account as done in the present study. We believe that more studies in this field are necessary to guide political decision-making in an effort to ensure equal care for equal needs. However, if other researchers reproduce our findings, it could hold broad implications for practice and policy. Irrespective of whether a society pursues the ideal of equal care for equal need or shares in opposing letting circumstances affect the level of care, our study suggests that there are still important and significant differences. Our results suggest that special attention should be paid to people who are old, retired and/or living alone to ensure that they get the recommended care. Similarly, the present study suggests that the system should pay more attention to those with low BMI to ensure that their needs are also meet.

\section{CONCLUSIONS}

Moving beyond classic socioeconomic factors to include a wider range of patient characteristics and more importantly characteristics that can be affected by the individual, 
such as BMI or alcohol intake, provided a better understanding of healthcare inequalities. Understanding how these different factors contribute to healthcare inequalities for equal needs could help to focus political and clinical attention in an effort to enhance equality in the provision of best clinical practice.

We found no evidence of a negative attitude towards obese stroke patients, but rather towards underweight stroke patients. The system actually favoured patients who had not exerted full responsibility over their own health as the obese stroke patients were more likely to receive the best clinical practice.

\section{Ethics approval and consent to participate}

This study was conducted in agreement with the Act on the Processing of Personal Data (Danish Data Protection Agency journal number 2015-57-0002). Because of the nature of the study, approval from the ethics committee was not required according to Danish law.

\section{References}

Albertsen, A. (2020) 'Personal Responsibility in Health and Health Care: Luck Egalitarianism as a Plausible and Flexible Approach to Health', Political Research Quarterly, 73(3).

Andersen, K. K. and Olsen, T. S. (2015) 'The obesity paradox in stroke: Lower mortality and lower risk of readmission for recurrent stroke in obese stroke patients', International Journal of Stroke, 10(1), pp. 99-104.

Bartlett, J. W., Harel, O. and Carpenter, J. R. (2015) 'Practice of Epidemiology Asymptotically Unbiased Estimation of Exposure Odds Ratios in Complete Records Logistic Regression', American Journal of Epidemiology, 182(8), pp. 730-736.

Blundell, J. E. et al. (2017) 'Variations in the Prevalence of Obesity Among European Countries, and a Consideration of Possible Causes', Obesity Facts, The European Journal of Obesity, 10, pp. 25-37.

Boehme, A. K., Esenwa, C. and Elkind, M. S. V (2017) 'Stroke Risk Factors, Genetics, and Prevention', Circulation Research, 120, pp. 472-495.

Budd, G. M. et al. (2011) 'Health care professionals' attitudes about obesity: An integrative review', Applied Nursing Research, 24, pp. 127-137.

Carlsen, F. and Martin, O. (2015) 'The relationship between educational attainment and waiting time among the elderly in Norway', Health Policy, 119, pp. 1450-1458.

Carrieri, V. and Jones, A. M. (2018) 'Inequality of opportunity in health: A decomposition-based approach', Health economics, 27(12), pp. 1981-1995.

Chen, R. et al. (2014) 'Socioeconomic deprivation and provision of acute and long-term care after stroke: The South London Stroke Register cohort study', Journal of Neurology, Neurosurgery \& Psychiatry, 85, pp. 1294-1300.

Chen, X. et al. (2014) 'Risk Factors of Stroke in Western and Asian Countries: A Systematic Review and Meta-analysis of Prospective Cohort Studies', BMC Public Health, 14.

Cox, A. M. et al. (2006) 'Socioeconomic status and stroke', Lancet Neurology, 5(2), pp. 181-188.

Dansk selskab for apopleksi, (2013) 'Referenceprogram for behandling af patienter med apopleksi og TCI',København, pp. 1-128.

Davillas, A. and Jones, A. M. (2020) 'Ex ante inequality of opportunity in health, decomposition and distributional analysis of biomarkers', Journal of Health Economics. 69, p. 102251.

Donnelly, S. and Verkuilen, J. (2017) 'Empirical logit analysis is not logistic regression Empirical logit analysis is not logistic regression', Journal of Memory and Language. 94(June), pp. 28 42 . 
Van Doorslaer, E., Masseria, C. and Koolman, X. (2006) 'Inequalities in access to medical care by income in developed countries', Cmaj, 174(2), pp. 177-183.

Eden, S. V et al. (2008) 'Racial and Ethnic Disparities in the Treatment of Cerebrovascular Diseases: Importance to the Practicing Neurosurgeon', Neurocrit Care, 9, pp. 55-73.

Eyal, N. (2013) 'Denial of treatment to obese patients-the wrong policy on personal responsibility for health', International Journal of Health Policy and Management, 1(2), pp. 107-110.

Feiring, E. (2008) 'Lifestyle , responsibility and justice', Journal of Medical Ethics, 34(1), pp. $33-$ 36.

Fleurbaey, M. and Schokkaert, E. (2009) 'Unfair inequalities in health and health care', 28, pp. 73-90.

Friesen, P. (2018) 'Personal responsibility within health policy: Unethical and ineffective', Journal of Medical Ethics, 44(1), pp. 53-58.

Gart, J. J. and Zweifel, J. R. (1967) 'On the Bias of Various Estimators of the Logit and Its Variance with Application to Quantal Bioassay', Biometrika, 54(1), pp. 181-187.

Grossman, M. (1972) 'On the Concept of Health Capital and the Demand for Health', Journal of Political Economy, 80(2), p. 223.

Hyldgård, V. B. et al. (2019) 'Socioeconomic Status And Acute Stroke Care: Has The Inequality Gap Been Closed?', Clinical Epidemiology, 11, p. 933—941.

Ingeman, A. et al. (2017) 'Lifestyle Factors and Early Clinical Outcome in Patients With Acute Stroke', Stroke, 48, pp. 1-7.

Johnsen, S. P. et al. (2016) 'The Danish stroke registry', Clinical Epidemiology, 8, pp. 697-702.

KCEB-Nord (2014) Dansk Apopleksiregister Arsrapport 2013 Endelig udgave.

Kimball, M. M. et al. (2014) 'Race and Income Disparity in Ischemic Stroke Care: Nationwide Inpatient Sample Database , 2002 to 2008', Journal of Stroke and Cerebrovascular Diseases, 23(1), pp. 17-24.

Kjellén, M., Von Euler-Chelpin, M. and von Euler-Chilpin, M. (2010) 'Socioeconomic status as determinant for participation in mammography screening: assessing the difference between using women's own versus their partner's', International journal of Public Health, 55(55), pp. 209-215.

Langagergaard, V. et al. (2011) 'Socioeconomic Differences in Quality of Care and Clinical Outcome After Stroke: A Nationwide Population-Based Study', Stroke, 42, pp. 2896-2902.

Libungan, B. et al. (2014) 'Delay and inequality in treatment of the elderly with suspected acute coronary syndrome', International Journal of Cardiology, 176(3), pp. 946-950.

Lindenstrøm, E. et al. (1991) 'Reliability of Scandinavian Stroke Scale', Cerebrovascular Diseases, 1(2), pp. 103-107.

Lutfey, K. E. et al. (2008) 'How are patient characteristics relevant for physicians' clinical decision making in diabetes? An analysis of qualitative results from a cross-national factorial experiment', Social Science and Medicine, 67(9), pp. 1391-1399.

Lynge, E., Sandegaard, J. L. and Rebolj, M. (2011) 'The Danish National Patient Register', Scandinavian journal of public health, 39(7 Suppl), pp. 30-33.

McCullagh, P. and Nelder, J. . (1989) Generalized Linear Models. Second edition. London: Chapman \& Hall.

Morris, S., Sutton, M. and Gravelle, H. (2005) 'Inequity and inequality in the use of health care in England: an empirical investigation', 60, pp. 1251-1266.

Nielsen, L. and Axelsen, D. V. (2012) 'Three strikes out: Objections to Shlomi Segall's luck egalitarian justice in health', Ethical Perspectives, 19(2), pp. 307-16. 
Palnum, K. D. et al. (2008) 'Older patients with acute stroke in Denmark: quality of care and short-term mortality. A nationwide follow-up study', Age and Ageing, 37(1), pp. 90-95.

Palnum, K. D. et al. (2009) 'Sex-Related Differences in Quality of Care and Short-Term Mortality Among Patients With Acute Stroke in Denmark: A Nationwide Follow-Up Study', Stroke, 40(4), pp. 1134-1139.

Petersson, F., Baadsgaard, M. and Thygesen, L. C. (2011) 'Danish registers on personal labour market affiliation.', Scandinavian journal of public health, 39(7 Suppl), pp. 95-8.

Robstad, N., Söderhmn, U. and Fegran, L. (2018) 'Intensive care nurses' experiences of caring for obese intensive care patients : A hermeneutic study', Journal of Clinical Nursing, 27, pp. 386395.

Roemer, J. E. (1993) 'A Pragmatic Theory of Responsibility for the Egalitarian Planner', Philosophy \& Public Affairs, 22(2), pp. 146-166.

Schmidt, H. (2008) 'Bonuses as incentives and rewards for health responsibility: A good thing?', Journal of Medicine and Philosophy, 33(3), pp. 198-220.

Schütte, S. et al. (2018) 'Participation in lung cancer screening programs: Are there gender and social differences? A systematic review', Public Health Reviews. Public Health Reviews, 39(1), pp. 1-12.

Siciliani, L. and Verzulli, R. (2009) 'Waiting times and socioeconomic status among elderly europeans: Evidence from share', Health economics, 18, pp. 1295-1306.

Søgaard, R. and Lindholt, J. S. (2019) 'Assessment of Inequality Alongside Policy-oriented Trials An Empirical Framework Based on the Case of Screening', Epidemiology, 30(5), pp. 706712.

Starr, L. K. et al. (2013) 'Socioeconomic position and surgery for early-stage non-small-cell lung cancer: A population-based study in Denmark', Lung Cancer, 79(3), pp. 262-269.

Sterne, J. A. C. et al. (2009) 'Multiple imputation for missing data in epidemiological and clinical research: potential and pitfalls', Bmj, 338(7713), pp. 1-10.

Terraneo, M. (2015) 'Inequities in health care utilization by people aged 50+: Evidence from 12 European countries', Social Science and Medicine. 126, pp. 154-163.

Tinghög, G., Carlsson, P. and Lyttkens, C. H. (2010) 'Individual responsibility for what? - A conceptual framework for exploring the suitability of private financing in a publicly funded health-care system', Health Economics, Policy and Law, 5(2), pp. 201-223.

Vassileva, C. M. et al. (2013) 'Relationship between Patient Income Level and Mitral Valve Repair Utilization', Heart Surgery Forum, 16(2).

Wildenschild, C. et al. (2013) 'Registration of acute stroke: Validity in the Danish stroke registry and the Danish national registry of patients', Clinical Epidemiology, 6, pp. 27-36.

(C) 2020 by the author(s). This article is an open access article distributed under the terms and conditions of the Creative Commons Attribution license (http://creativecommons.org/licenses/by/4.0/). 